\title{
Electrochemical Method for Heavy Metals Detection by Inhibition of Acetylcholinesterase Immobilized on Pt-nanoparticles Modified Graphite Electrode
}

\author{
G. L. Turdean $^{1}$ and I. C. Popescu ${ }^{1}$ \\ Department of Physical Chemistry, University “Babes-Bolyai”, RO-400028 Cluj-Napoca, ROMANIA, \\ gturdean@chem.ubbcluj.ro
}

\begin{abstract}
The optimization and the characterization of a new amperometric biosensor based on acetylcholinestrase (AChE), immobilized on a graphite electrode modified with Pt-nanoparticles (PtNP), are reported. The G/PtNP-AChE biosensor was used for heavy metals detection. The degree of inhibition (\%I), the kinetic constants of the inhibition process, as well as the influence of the PtNP presence on these parameters were estimated.
\end{abstract}

Key words: Heavy metals, acetylcholinesterase, inhibition, wastewater.

\section{Introduction}

Heavy metal detection in environmental control is usually performed by spectroscopic, electrochemical or chromatographic methods (Malitesta and Gauscito, 2005), which are able to identify single elements and/or species at low concentrations, but can hardly be used for in-situ analysis and/or low-cost screening methods. Also, these tasks can be successful accomplished using biosensors. Thus, the enzyme biosensors used for the detection of commonly analytes in clinical and food analysis are based on the direct specific interaction between enzyme and substrate. Contrarily, in environmental analysis pollutants (e.g. pesticides, heavy metals etc.) the detection caused by the toxic substances is based on the inhibition of the enzymatic activity. The reduced specificity of inhibition phenomenon makes possible only the estimation of the sum parameters, i.e. total concentration of the substances belonging to a certain class. Because of their high specificity, it is expected that biosensor detects only contaminants, which are pollutant to life.

The aim of this work is to build-up and the subsequent application of a new amperometric biosensor based on acetylcholinesterase (AChE) immobilized on a graphite electrode modified with Pt-nanoparticles (PtNP) for heavy metals detection by using voltammetric techniques.

\section{Materials and Methods}

Acetylcholinesterase (EC. 3.1.1.7) and acetylthiocholine chloride were obtained from Sigma. $\mathrm{Na}_{2} \mathrm{HPO} 4, \mathrm{NaH}_{2} \mathrm{PO} 4$, EDTA disodium salt, copper (II) sulphate, cadmium (II) nitrite, chromium (III) nitrite, Zn(II) sulphate were from Reactivul-Bucuresti. The buffer solution and the heavy metals standard solutions were prepared by dissolving the appropriate amount of salts in distilleted water. The Pt-nanoparticles (PtNP) were a kindly gift received from prof. Dan Goia (Clarkson University, New York, USA), which is greatley acknowledged. Chitosan and Nafion were used as polymer matrix for immobilizing the active components of biosensor. The analysed wastewater was supplied by a nearby galvanisation factory.

Electrochemical experiments were carried out with a voltammetric analyser AUTOLAB PGSTAT 10 (Eco Chemie, Holland), connected to a PC computer. A graphite (inner diameter $3 \mathrm{~mm}$ from Ringsdorff, Germany) or platinum support electrode was modified by immobilizing the enzyme and the PtNP into a polymer matrix and were used as working electrode. $\mathrm{An} \mathrm{Ag} / \mathrm{AgCl}$, $\mathrm{KCl}_{\text {sat }}$ (Radiometer) and a platinum wire were used as refecrence and counter electrode, respectively.

All voltammetric measurements were performed in the presence of dissolved oxygen. The working electrode was immersed into a $10 \mathrm{ml}$ cell containing $0.1 \mathrm{M}$ 
phosphate buffer. A background voltammogramm was recorded prior to the addition of corresponding aliquots of heavy metals standard solution or of wastewater sample. The preconcentration step consist in applying a deposition potential (usually $-1.5 \mathrm{~V}$ ) for a $120 \mathrm{~s}$ period and after in recording a voltammogram when a positive going square wave voltammetric (SWV) scan is applied with a frequency of $50 \mathrm{~Hz}$, potential step of $5 \mathrm{mV}$ and amplitude of $50 \mathrm{mV}$. All experiments were performed at room temperature.

The amperometric experiments were caried out in a stirred solution of phosphate buffer $(\mathrm{pH} \mathrm{7})$ at a $+0.4 \mathrm{~V} v s$. $\mathrm{Ag} / \mathrm{AgCl}, \mathrm{KCl}_{\text {sat }}$ to the working electrode.

\section{Results and Discussion}

On recorded SWVs well-defined peaks were observed together with low background currents, although no sample de-aeration was undertaken. Linear calibration curves having good correlation coefficients were obtained. The reproducibility and the robustness of the biosensor were also investigated (Legeai and Vittori, 2006).

The kinetic analysis of the results obtained with amperometric method is based on the experimental data collected by recording the current intensity of the biosensor corresponding to the produced thiocholine before and after addition of heavy metals solution. The thiocholine is the product of the hydrolysis reaction of acetylthiocholine catalysed by immobilized acetylcholinesterase on the surface of the working electrode (figure 1) corresponding to the following reaction (Stoytcheva and Sharkova, 2002:

\section{$\left(\mathrm{CH}_{3}\right)_{3} \mathrm{~N}^{+}\left(\mathrm{CH}_{2}\right)_{2} \mathrm{SCOCH}_{3}+\mathrm{H}_{2} \mathrm{O} \rightarrow\left(\mathrm{CH}_{3}\right)_{3} \mathrm{~N}^{+}\left(\mathrm{CH}_{2}\right)_{2} \mathrm{SH}+$ $\mathrm{CH}_{3} \mathrm{COOH}$}

Fig. 1. Schematic diagram representing the exchange of electrons during the oxidation of thiocholine (RSH) on

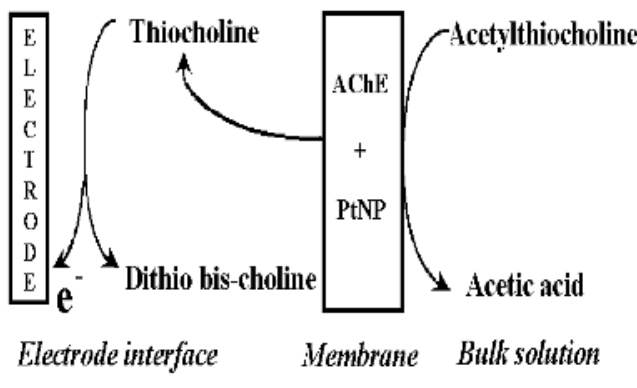

\section{PtNP-AChE/G electrode}

The results of inhibition of enzyme by the presence of heavy metals are the decrease of the generated thiocholine concentration.

The effect of inhibition exerted by the heavy metals was quantitatively estimated by the degree of inhibition (I, \%) which was calculated by using the following equation: $\% \mathrm{I}=\Delta \mathrm{I} \times 100 / \mathrm{I}_{0}$, where: $\Delta \mathrm{I}$ is the difference between the current intensities recorded in the presence and in the absence of heavy metals and $I_{0}$ is the current intensity in the absence of heavy metals.

The graphic analysis of the experimental data following the Hanes-Woolf linearization method demonstrated the type of inhibition of acetylcholinesterase by the tested heavy metals. The inhibition process of the immobilised enzyme can be described by the following kinetic scheme:

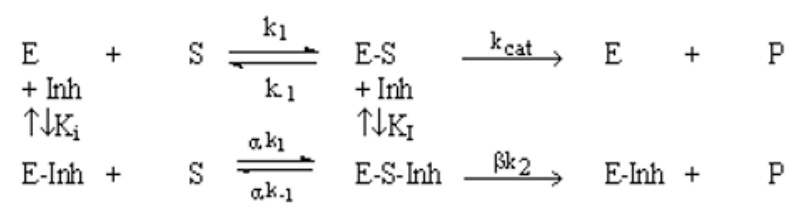

where: $\mathrm{E}$ is the immobilised enzyme; $\mathrm{S}$ is the free substrate, here $\mathrm{ASChCl} ; \mathrm{P}$ is the product, here thiocholine; E-S is the enzyme-substrate complex; E-Inh is the enzyme-inhibitor complex; E-S-Inh is the ternary complex containing enzyme-substrate-inhibitor; $\mathrm{K}_{\mathrm{I}}$ and $\mathrm{K}_{\mathrm{I}}$ are the equilibrium dissociation constants of the E-S-Inh complex and the E-Inh complex, respectively.

Thus, if the secondary plots of the slope $v s$. [Inh] and the $1 / \mathrm{I}$ axis intercepts $v s$. [Inh] (i.e. $1 / \mathrm{I}_{\max \text {,inh }} v s$. [Inh] and $\mathrm{K}_{\mathrm{M} \text {,inh }} / \mathrm{I}_{\max \text {,inh }} v s$. [Inh], respectively) (Trevor Palmer, 1987) are linear, they allow to estimate the values of $K_{I}$ and $\mathrm{K}_{\mathrm{i}}$, respectively, from a single set of experimental data.

The influence of the PtNP presence on the inhibition response was also evaluated.

\section{Conclusion}

The proposed Pt-NP-AChE/G electrode was applied to detect heavy metals $(\mathrm{Cu}, \mathrm{Cd}, \mathrm{Cr}, \mathrm{Zn})$ in synthetic and real samples of wastewater. The bioelectrochemical methods for acetylcholinesterase inhibitor analysis, due to their simplicity, rapidity and sensitivity could be an alternative to the sophisticated classical tests applied for environmental monitoring.

\section{Acknowledgements}

The authors thank the financial supports providing from CNCSIS - Romania (Project PN-II-ID_PCCE_129/ 2008).

\section{References}

Legeai $\mathrm{S}$ and Vittori $\mathrm{O}$. A $\mathrm{Cu} / \mathrm{Nafion} / \mathrm{Bi}$ electrode for on-site monitoring of trace heavy metals in natural waters using anodic stripping voltammetry: An alternative to mercury-based electrodes, Anal. Chim. Acta 2006; 560:184-190

Malitesta C, Gauscito MR. Heavy metal determination by biosensors based on enzyme immobilised by electropolymerisation, Biosens. Bioelectron. 2005; 20:1643-1647.

Stoytcheva M and Sharkova V. Kinetics of the inhibition 
of immobilized acetylcholinesterase with $\mathrm{Hg}(\mathrm{II})$, Electroanalysis 2002; 14:1007-1010.

Trevor Palmer BA. Understanding Enzymes. Ellis
HorWood Ltd.. Chichester West Sussex. 2nd. Ed., 1987, p. 142-160. 